\title{
Electrochemical Polymerization of Aniline in High Magnetic Fields
}

\author{
Iwao MoGI
}

Received June 2, 1994 ; Accepted July 14, 1994

\section{INTRODUCTION}

Magnetic field effects on chemical reactions have been of scientific interest for a long time. Clear evidence for the effect, however, has so far been reported in a few chemical reactions: A radical pair undergoes the strong modification of its reaction path in the magnetic field which changes the crossing rate between the singlet and triplet states ${ }^{1}$. On the other hand, the magnetic field induces orientation of most organic molecules, especially organic polymers because they have anisotropic diamagnetic susceptibility ${ }^{2)}$.

Aniline is oxidized in an acidic solution to form electroactive polyaniline (PA) films $\mathrm{s}^{3}$. This electrochemical reaction includes polymerization of cation radicals and film formation of the polymers. In this paper we examined the electrochemical impedance of aniline in magnetic fields higher than $10 \mathrm{~T}$ to investigate the magnetic field effect on the electrochemical polymerization.

\section{EXPERIMENTAL}

The electrochemical experiments with high magnetic fields were performed at the High Field Laboratory of Tohoku University. A scheme of the electrochemical cell with a magnet is shown in Fig.1. Magnetic fields were generated vertically by a water-cooled resistive magnet (Bitter solenoid) with the maximum field of $15 \mathrm{~T}$ at the maximum current of $21 \mathrm{kA}$. A platinum disk electrode with a diameter of $1.6 \mathrm{~mm}$ was used as

Institute for Materials Research, Tohoku University, (Sendai 980-77, Japan)

Key words; Aniline, Electrochemical Polymerization, High Magnetic Field, Ac Impedance

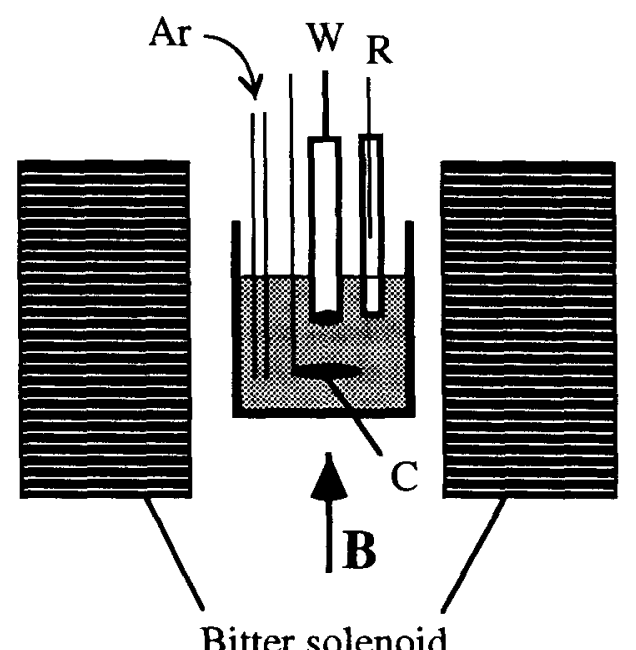

Fig.1 Schematic diagram of the electrochemical cell in high magnetic fields B. W; working electrode, $R$; reference electrode, $C$; counter electrode.

a working electrode (W), a $\mathrm{Ag} / \mathrm{AgCl}$ electrode as reference electrode $(R)$ and a platinum plate as a counter electrode (C). These electrodes were arranged so that the current flows vertically in the solution, preventing the Lorentz force from inducing the magnetohydrodynamic (MHD) convection ${ }^{4)}$.

All chemicals were of guaranteed reagent grade. The electrochemical measurements were carried out by an electrochemical analyzer BAS100B. In-situ electrochemical impedance was measured during potentiostatic deposition by means of the noise-FFT method over a frequency range from $1 \mathrm{~Hz}$ to $1 \mathrm{kHz}$. The test solutions were deaerated for $30 \mathrm{~min}$ by argon gas be- 
fore measurements. Temperature was controlled at $25.0 \pm 0.1{ }^{\circ} \mathrm{C}$ by a water-circulating system.

\section{RESULTS AND DISCUSSION}

Figure 2 shows cyclic voltammograms at $0 \mathrm{~T}$ and $12 \mathrm{~T}$ of $50 \mathrm{mM}\left(\mathrm{M}=\mathrm{mol} \cdot \mathrm{dm}^{-3}\right)$ aniline in a 0.5 $\mathrm{M} \mathrm{H}_{2} \mathrm{SO}_{4}$ aqueous solution. The voltammograms are irreversible because aniline is oxidized, being PA. The peak current appreciably increases in the magnetic field, suggesting that the magnetic field accelerates the electrode reaction.

The PA films were electrodeposited on the Pt electrode at $+1.1 \mathrm{~V}$ in $50 \mathrm{mM}$ aniline $/ 0.5 \mathrm{M}$ $\mathrm{H}_{2} \mathrm{SO} 4$. Figure 3 shows cyclic voltammograms of the PA films in a $0.5 \mathrm{M} \mathrm{H}_{2} \mathrm{SO}_{4}$ solution at $0 \mathrm{~T}$, where the films were electrodeposited by $10 \mathrm{mC}$ at $0 \mathrm{~T}$ or $10 \mathrm{~T}$. Redox peaks of PA itself ${ }^{5)}$ are seen from +0.2 to $+1.0 \mathrm{~V}$, and both films show the same voltammetric behavior.

On the contrary, the behavior of in-situ electrochemical impedance has been found to be considerably different between the electrodeposition of the PA films with and without magnetic field. Figure 4 shows the Cole-Cole plots obtained by the in-situ ac impedance measurements during the potentiostatic deposition of PA at +1.1 $\mathrm{V}$ in $50 \mathrm{mM}$ aniline / $0.5 \mathrm{M} \mathrm{H}_{2} \mathrm{SO}_{4}$ in $0 \mathrm{~T}$ and 12 $\mathrm{T}$, where the ac impedance was measured at +1.1 $\mathrm{V}$ with the ac voltage of $10 \mathrm{mV}$ (peak-to-peak); (a) before electrodeposition, (b) at $10 \mathrm{mC}$ and (c) at $50 \mathrm{mC}$. Before the electrodeposition, the Cole-Cole plots show the Randles type, as

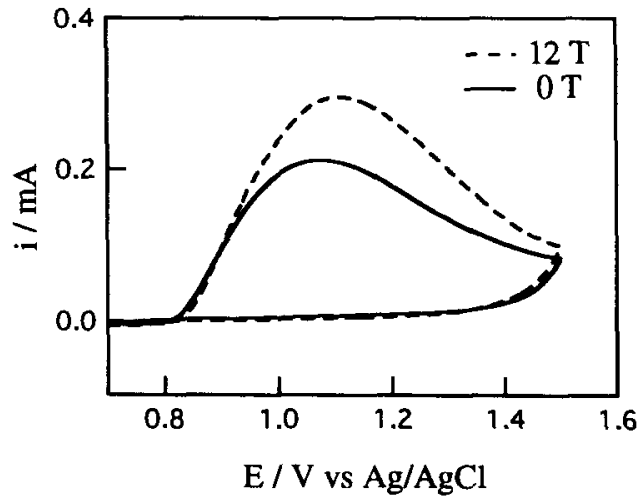

Fig.2 Cyclic voltammograms of $50 \mathrm{mM}$ aniline in a $0.5 \mathrm{M} \mathrm{H} 2 \mathrm{SO}_{4}$ solution at $0 \mathrm{~T}$ and $12 \mathrm{~T}$. Scan rate is $100 \mathrm{mV} \cdot \mathrm{s}^{-1}$.

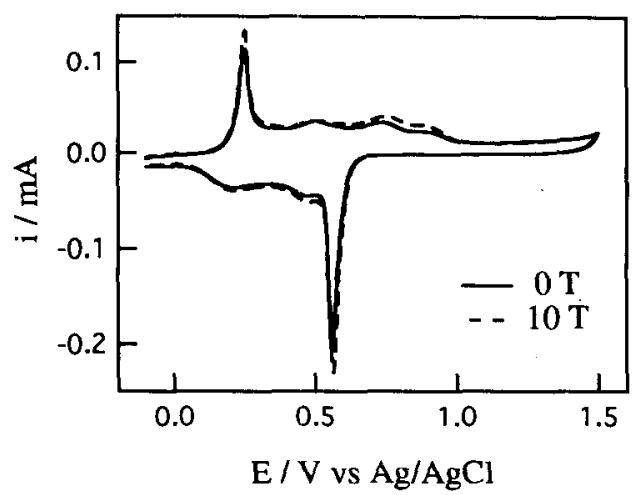

Fig.3 Cyclic voltammograms of polyaniline films on a Pt electrode in a $0.5 \mathrm{M} \mathrm{H}_{2} \mathrm{SO}_{4}$ solution at $0 \mathrm{~T}$. The films were electropolymerized by 10 $\mathrm{mC}$ at $0 \mathrm{~T}$ or $10 \mathrm{~T}$. Scan rate is $50 \mathrm{mV} \cdot \mathrm{s}^{-1}$.

clearly seen at $12 \mathrm{~T}$, and the reaction resistance gets smaller in the magnetic field. This is consistent with the current increase in the voltammogram in Fig.2. Once the PA film is formed on the electrode, the Cole-Cole plots show the reaction controlled behavior (Fig.4(b),(c)), and the reaction resistance increases with proceeding of the electrodeposition. The smaller reaction resistance at $12 \mathrm{~T}$ is more striking during the electrodeposition, and the difference between $0 \mathrm{~T}$ and $12 \mathrm{~T}$ enlarges with increasing thickness of the films.

If the small reaction resistance at $12 \mathrm{~T}$ is caused by the MHD convection, such effect should be most prominent before electrodeposition because the current is largest. The result is, however, opposite. In the present case the current is in the same direction of the magnetic field, and the MHD convection hardly arises in such arrangement.

It is well known that organic polymers have anisotropic diamagnetic susceptibility, hence being oriented in the magnetic field ${ }^{2}$. In the case of cunjugated systems the planes of the conjugated bonds tend to orient parallel to the magnetic field $^{2}$. It can be presumed that the aromatic plane of aniline orients parallel to the magnetic field in the electropolymerized films because of large diamagnetic susceptibility of the ring current. Thus, we considered that the small reaction resistance at $12 \mathrm{~T}$ is caused by the oriented growth of PA. The slight difference between $0 \mathrm{~T}$ 
and $12 \mathrm{~T}$ before electrodeposition (Fig.4(a)) is probably due to the film formation during the ac impedance measurements. The morphological investigation of the films is in progress.
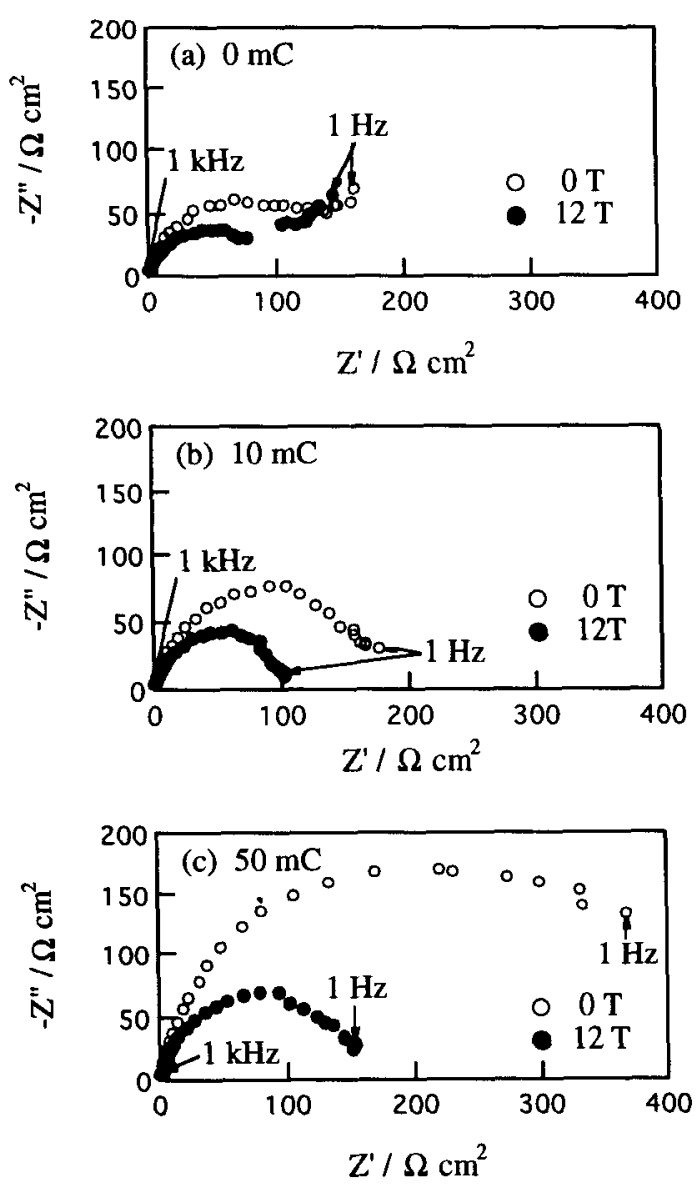

Fig.4 In-situ ac impedance measurements during the electrodeposition of polyaniline at $+1.1 \mathrm{~V}$ in $50 \mathrm{mM}$ aniline / $0.5 \mathrm{M} \mathrm{H} 2 \mathrm{SO} 4$ in $0 \mathrm{~T}$ and $12 \mathrm{~T}$. (a); before electrodeposition, (b); at $10 \mathrm{mC}$, (c); at $50 \mathrm{mC}$.
There remains an open question why no magnetic field effect is observable in the voltammograms of the PA film itself (Fig.3) despite the remarkable change in the in-situ ac impedance (Fig.4).

In summary, we introduced the high magnetic fields into the electrochemical cell and electrodeposited PA films, which showed remarkably small reaction resistance in the in-situ ac impedance measurements.

The author wish to thank all staff members of the High Field Laboratory of Tohoku University for operating the magnet. This work was supported in part by Grant-in-Aid for Scientific Research on Priority Areas (No. 236) from the Ministry of Education, Science and Culture and the Foundation Advanced Technology Institute.

\section{REFERENCES}

1) K.M. Salikhov, Yu.N. Molin, R.Z. Sagdeev and A.L. Buchachenko, "Spin Polarization and Magnetic Effects in Radical Reaction", ed. Yu. N. Molin, (Elsevier, Amsterdam, 1984).

2) G. Maret and K. Dransfeld, "Strong and Ultrastrong Magnetic Fields and their Applications" ed. F. Herlach, Springer-Verlag, Berlin Heidelberg (1985) p143.

3) T. Ohsaka, Y. Ohnuki, N. Oyama, G. Katagiri and K. Kamisako, J. Electroanal. Chem., 161, 399 (1984).

4) R. Aogaki, K. Fueki and T. Mukaibo, Denki Kagaku, 43, 504, 509 (1975).

5) N. Oyama, Y. Ohnuki, K. Chiba and T. Ohsaka, Chem. Lett., 1759 (1983). 